\title{
PlíNIO O JoVEM E A TRADUÇÃO NA ANTIGUIDADE - EPISTULAE VII, 9; IV, 18; V, 15 (SÉC. II) -
}

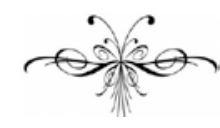

PLINIUS MiNOR

MAURI FURLAN (TRADUTOR)

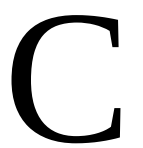

aius Plinius Caecilius Secundus, ou Plinius Minor, Plínio o Jovem $^{1}$ (ca.61-114), natural de Comum (atual Como, na Lombardia), foi orador, poeta, jurista, político e governador da Bitínia, na Ásia Menor. É mais conhecido como escritor, sobretudo por seu epistolário, um conjunto de 368 cartas, que formam dez livros, nas quais revela detalhes de sua vida em Roma e no campo, as palestras públicas, os literatos, a leitura e a vida social da época. De sua correspondência com o imperador Trajano, deu-nos a conhecer sobre o governo romano das províncias da época. É de Plínio um dos principais documentos sobre a erupção do Vesúvio, que destruiu Pompeia no ano 79 (Epistulae VI, 16), durante a qual faleceu seu tio materno e pai adotivo Plínio o Velho (23-79) (Epistulae VI, 20), e também um dos primeiros documentos não neotestamentários sobre a igreja primitiva dos cristãos (Epistulae $X, 95$; 96). Suas cartas foram escritas entre 97 e 109, numa época de paz política, sob o governo de Trajano.

Redigiu suas cartas para serem publicadas, e cada uma aborda geralmente um único tema. Como escritor é considerado um bom literato, neoclássico, estóico, engenhoso, mas de segunda ordem. Embora tenha tomado Cícero como seu modelo, não foi além de um imitador, e de seu estilo e de suas cartas diz-se que

lacking the vivacity and directness of his model, and, of course, wholly deficient in the political interest which makes Cicero's correspondence one of the most important authorities for the history of his troublous time. (Firth, 2008:11) ${ }^{2}$

\footnotetext{
${ }^{1}$ Os principais manuais de literatura latina que consultamos são: BASSI, I. \& CABRINI, P. Manuale di letteratura latina ad uso dei licei. Vol. II. Torino: Ditta G. B. Paravia, 1916, p. 229-248. BAYET, Jean. Literatura latina. Trad. de José-Ignacio Ciruelo. Barcelona: Editorial Ariel, 1996, p. 393-399; CORTE, Francesco della. Sommario storico della letteratura latina. Torino: Loescher Editore, 1972, pp. 427-431; GRIMAL, Pierre. La littérature latine. Paris: Fayard, 1994, p. 468-476; Vitelli, Girolamo \& MAzzoni, Guido. Manuale della letteratura latina. Firenze: Barbera Editore, 1912, p. 549-559.

${ }^{2}$ FIRTH, John B. "Introductory Essay" in Pliny the Younger, The Letters of the Younger Pliny. Maryland: Wildside Press, 2008, pp. 11-30.
} 
In Plinio ogni frase, ogni parola è pesata, studiata, perchè egli pregusta l'effeto che dovrà fare sull'animo del lettore. Così tutto è affettato e poco sincero. (Bassi \& Cabrini, 1916:234)

Contemporâneo de nomes como Marcial, Tácito, Juvenal e Suetônio, Plínio, contudo, produz uma escritura que difere muito daquela dos autores citados. Mas, apesar de não ser incluído entre os grandes escritores, é uma das figuras mais importantes de sua época. Em Roma, fora discípulo dos afamados mestres Quintiliano e Nicetes Sacerdos de Smyrna, e seu pensamento acerca de linguagem e tradução, expresso em suas correspondências, reflete concepções quintilianas.

Plínio não produziu nenhuma longa ou sistemática reflexão sobre tradução. Sua opinião a respeito, representativa de toda a época clássica, de Cícero a Quintiliano, encontra-se em grande parte numa carta endereçada a um advogado, Fuscus Salinator, filho de um procônsul da Ásia, de mesmo nome. A carta (VII, 9), escrita provavelmente na primeira década do século II, é uma resposta ao jovem que lhe solicitava conselhos sobre como desenvolver suas habilidades oratórias mediante exercícios a seguir durante uma estadia no campo. Dentre várias atividades recomendadas, a tradução é referida em primeiro lugar. Mas deve-se notar que, em sua abordagem, a menção a elementos pertencentes à gramática e à retórica expressa componentes envolvidos na concepção e prática não só da tradução, mas também do comentário, da imitação e da emulação então produzidas, operações que se sobrepõem e se entremesclam. E, sobretudo, - insistimos -, que o tratamento dado ao assunto na carta corresponde à proposta de oferecer a tradução como um tipo de exercício para desenvolver a habilidade literária, não de produzir uma tradução literária, embora possamos reconhecer pontos fundamentais de uma concepção histórica comum sobre tradução. Uma importante diferença está em que na tradução como exercício busca-se exclusivamente o benefício do exercitante, e, na prática da tradução literária, também o da obra e do leitor. Podemos elencar assim aqueles elementos referidos com os quais se pode exercitar: propriedade e esplendor das palavras; riqueza das figuras; força da expressão; capacidade de criar a partir da imitação; leitura atenta; retomada do assunto e argumento de outro; comparação e cuidadoso exame; disputa com o modelo; superação do modelo, emulação; conservação, abandono, interposição, reescritura de partes; estilo; conteúdo e forma; poesia e prosa; autores e gêneros.

Ademais da carta a Fusco, que apresenta a tradução, o comentário, a imitação e a emulação como exercícios oratórios, outras duas cartas de curta extensão (IV,18; V,15), dirigidas a seu amigo e cônsul Arrio Antonino, assinalam dois outros temas concernentes ao traduzir: o da pobreza da língua pátria ante a língua estrangeira, e o da incompetência do tradutor (imitador/emulador) que produz uma obra inferior ao modelo: temas frequentes desde sempre.

Para contextualizar o pensamento de Plínio sobre tradução é importante ter presente que, na Antiguidade romana, a concepção de tradução é formada no âmbito da retórica e da gramática e na relação entre essas duas disciplinas. Na teoria pedagógica de então, a tradução estava intimamente ligada à teoria e prática da imitação de modelos literários. Nos estudos gramaticais, a tradução era considerada um aspecto do comentário textual; nos estudos retóricos, era uma forma de imitação. Daí também a sobreposição entre as práticas de comentário, tradução e imitação. 
As duas artes da língua, a gramática e a retórica, eram definidas respectivamente como ars recte loquendi (a arte de falar corretamente) e ars bene loquendi (a arte de falar bem). Na primeira se estudavam os aspectos que possibilitam a comunicação; na segunda, os aspectos que tornam a comunicação efetiva. E dentro da teoria geral da linguagem da época, que concebia a linguagem como uma 'construção', o ponto de partida era a palavra, cuja escolha era determinada por critérios como os de propriedade, pureza, e clareza. Uma vez selecionadas e classificadas, as palavras construíam o texto sob as regras da gramática, relativas à interpretação textual e à sintaxe, passando em seguida pelas técnicas da retórica, que cuidava da efetivação da mensagem, mediante os recursos oferecidos pela disciplina, previstos sobretudo em suas três primeiras partes, inuentio, dispositio, elocutio, que tratavam basicamente do assunto, dos argumentos, da disposição e ordenação das partes do discurso, e de sua apresentação estético-formal. O fim de tudo era a produção literária.

Há ao menos dois pontos fundamentais a considerar em uma análise que envolve a concepção de tradução entre os romanos: (1) a concepção de linguagem, e consequentemente de tradução, na Antiguidade Clássica é a chamada inuentioelocutio (tomada da retórica clássica), ou seja, a que dá ênfase tanto ao tema e aos argumentos, quanto à estética formal, e (2) o papel da mímesis na criação literária da Antiguidade, que julgava as artes pelo nível de trabalho que apresentavam e pela sua eficácia na realização de seus propósitos, desconsiderando a ideia de criatividade artística, no sentido moderno, bem como a ideia de arte enquanto expressão da personalidade do artista. Mais importava a habilidade ou técnica com que um tema era tratado do que ser o primeiro em apresentá-lo. O texto era considerado aberto, e a marca pessoal do autor devia se mostrar no estilo. Nesse contexto, a prática da tradução literária e da imitação era um exercício para a emulação, ou seja, a superação do modelo.

Na sociedade bilingue, ou mesmo trilingue, da Roma clássica, o leitor romano podia considerar a tradução como um metatexto do original, e o tradutor romano, que era julgado por sua habilidade em usar criativamente seu modelo, podia conceber a tarefa da tradução como um exercício de estilística comparada. Invenção romana, a tradução literária artística é reelaboração, é recriação da fonte grega, é apropriação, latinização.

Mauri Furlan 


\section{Epistula VII, 9}

\section{Plinius Fusco suo s.}

1 Quaeris quemadmodum in secessu, quo iam diu frueris, putem te studere oportere. 2 Utile in primis, et multi praecipiunt, vel ex Graeco in Latinum vel ex Latino vertere in Graecum. Quo genere exercitationis proprietas splendorque verborum, copia figurarum, vis explicandi, praeterea imitatione optimorum similia inveniendi facultas paratur; simul quae legentem fefellissent, transferentem fugere non possunt. 3 Intellegentia ex hoc et iudicium acquiritur. Nihil offuerit quae legeris hactenus, ut rem argumentumque teneas, quasi aemulum scribere lectisque conferre, ac sedulo pensitare, quid tu quid ille commodius. Magna gratulatio si non nulla tu, magnus pudor si cuncta ille melius. Licebit interdum et notissima eligere et certare cum electis. 4 Audax haec, non tamen improba, quia secreta contentio: quamquam multos videmus eius modi certamina sibi cum multa laude sumpsisse, quosque subsequi satis habebant, dum non desperant, antecessisse. 5 Poteris et quae dixeris post oblivionem retractare, multa retinere plura transire, alia interscribere alia rescribere. 6 Laboriosum istud et taedio plenum, sed difficultate ipsa fructuosum, recalescere ex integro et resumere impetum fractum omissumque, postremo nova velut membra peracto corpori intexere nec tamen priora turbare.

\section{Caio Plínio saúda Fusco}

1 Perguntas-me de que modo eu creia que te seja oportuno estudares em teu retiro, do qual já desfrutas há bom tempo. 2 É sobretudo útil, e muitos recomendam o traduzir, seja do grego ao latim, seja do latim ao grego. Com este tipo de exercício, busca-se a propriedade e o esplendor das palavras, a riqueza das figuras, a força da expressão, ademais da capacidade de criar de maneira similar a partir da imitação dos melhores. Ao mesmo tempo, o que tenha falhado ao leitor não pode escapar ao tradutor. 3 Obtém-se disso inteligência e discernimento. Não te fará mal se as coisas que então tiveres lido o foram com o fim de reter o assunto e o argumento, e, como um êmulo, as escreveres e comparares com as lidas, e examinares com cuidado o que tu fizeste mais convenientemente e o que ele. Grande será a alegria se em algumas coisas tu fores o melhor, grande a vergonha se ele em todas. Será permitido por vezes escolher as passagens mais célebres e disputar com as escolhidas. 4 Este confronto será audacioso, contudo não arrogante, porque secreto: no entanto vemos que muitos tomaram para si disputas deste tipo com muito mérito, e, porque não desesperançaram, precederam aos que tinham em grande consideração seguir. 5 Poderás também reconsiderar o que tiveres dito depois de já o teres esquecido, conservar muitas coisas, abandonar muitas mais, interpor umas, rescrever outras. 6 Trabalhoso e muito fastidioso, mas profícuo pela própria dificuldade, é aquele reaquecer e retomar de novo o ímpeto alquebrado e abandonado, enfim, aquele introduzir como que novos membros a um corpo já formado, e, contudo, sem perturbar os antigos. 
7 Scio nunc tibi esse praecipuum studium orandi; sed non ideo semper pugnacem hunc et quasi bellatorium stilum suaserim. Ut enim terrae variis mutatisque seminibus, ita ingenia nostra nunc hac nunc illa meditatione recoluntur. 8 Volo interdum aliquem ex historia locum apprendas, volo epistulam diligentius scribas. Nam saepe in oratione quoque non historica modo sed prope poetica descriptionum necessitas incidit, et pressus sermo purusque ex epistulis petitur. 9 Fas est et carmine remitti, non dico continuo et longo - id enim perfici nisi in otio non potest -, sed hoc arguto et brevi, quod apte quantas libet occupationes curasque distinguit. 10 Lusus vocantur; sed hi lusus non minorem interdum gloriam quam seria consequuntur. Atque adeo cur enim te ad versus non versibus adhorter?-

11 ut laus est cerae, mollis cedensque sequatur si doctos digitos iussaque fiat opus

et nunc informet Martem castamve Minervam, nunc Venerem effingat, nunc Veneris puerum; utque sacri fontes non sola incendia sistunt, saepe etiam flores vernaque prata iuvant, sic hominum ingenium flecti ducique per artes non rigidas docta mobilitate decet.

12 Itaque summi oratores, summi etiam viri sic se aut exercebant aut delectabant, immo delectabant exercebantque. 13 Nam mirum est ut his opusculis animus intendatur remittatur. Recipiunt enim amores odia iras misericordiam urbanitatem, omnia denique quae in vita atque etiam in foro causisque versantur. 14 Inest his quoque eadem quae aliis carminibus utilitas, quod metri necessitate devincti soluta oratione laetamur, et quod facilius esse comparatio ostendit, libentius scribimus. 15 Habes plura etiam fortasse quam requirebas; unum tamen omisi. Non enim dixi quae
7 Sei que tens agora como principal ocupação a de advogar; mas não por isso aconselharia sempre o estilo combativo e quase belicoso. Pois assim como as terras são cultivadas com várias e diversas sementes, também o é o nosso engenho ora com esse ora com aquele exercício retórico. 8 Gostaria que por vezes tomasses alguma passagem da história, por vezes escrevesses uma carta com maior cuidado. Pois frequentemente incide sobre o discurso também uma necessidade de descrições não somente históricas mas quase poéticas, e nas cartas é requerida uma linguagem sóbria e simples. 9 É lícito também distrair-se com a poesia, e não falo de uma contínua e longa (que só pode ser realizada no ócio), mas uma arguta e breve, que interrompe oportunamente quantas sejam as ocupações e cuidados. 10. São chamadas de 'jogos'; mas não menor glória estes jogos obtêm do que as poesias sérias. E, por tanto, por que não te incito aos versos com versos?

\footnotetext{
11 Qual elogio à cera, segue suave e cede Aos dedos doutos, torna-se obra prescrita; E ora molda Marte ou a casta Minerva, Ora a Venus conforma, ora o seu menino; Qual sagradas fontes não só detêm fogos E ajudam flores e prados primaveros; Ao engenho humano convém dobrar-se em Douta mobilidade n'artes não duras.
}

12 Por isso os grandes oradores, e também os grandes homens se exercitavam ou se deleitavam assim, ou melhor, deleitavam-se e exercitavam-se. 13 Pois é admirável como relaxa o espírito que se dedica a tais opúsculos. É que eles acolhem os amores, os ódios, as iras, a misericórdia, a urbanidade, tudo, enfim, que acontece na vida e também nas praças e tribunais. 14 Há neles também o mesmo recurso que em outras poesias, e, por conta da necessidade de métrica obrigatória, nos alegramos com a prosa, e porque a comparação mostra ser esta mais fácil, escre- 
legenda arbitrarer: quamquam dixi, cum dicerem quae scribenda. Tu memineris sui cuiusque generis auctores diligenter eligere. Aiunt enim multum legendum esse, non multa. 16 Qui sint hi adeo notum probatumque est, ut demonstratione non egeat; et alioqui tam immodice epistulam extendi, ut dum tibi quemadmodum studere debeas suadeo, studendi tempus abstulerim. Quin ergo pugillares resumis, et aliquid ex his vel istud ipsum quod coeperas scribis? Vale. vêmo-la de preferência. 15 Estás recebendo talvez muitas mais coisas do que pedias; uma, contudo, omiti. Pois não disse o que considero que deva ser lido: embora eu tenha dito quando dizia o que deveria ser escrito. Tu te lembrarás de escolher diligentemente os autores e o gênero de cada um deles. Dizse, pois, que se deve ler muito, não muitas coisas. 16 Quais sejam eles, até agora é sabido e provado que não é necessário uma demonstração; e por outro lado, alarguei esta carta tão exageradamente que enquanto te aconselho como deves estudar, roubo-te o tempo do estudo. Por que então não retomas a tabuinha, e escreves algo disto ou daquilo que tu mesmo começaste? Fica bem!

\section{Epistula IV, 18}

\section{Plinius Arrio Antonino suo s.}

1 Quemadmodum magis approbare tibi possum, quanto opere mirer epigrammata tua Graeca, quam quod quaedam Latine aemulari et exprimere temptavi? in deterius tamen. Accidit hoc primum imbecillitate ingenii mei, deinde inopia ac potius, ut Lucretius ait, egestate patrii sermonis. 2 Quodsi haec, quae sunt et Latina et mea, habere tibi aliquid venustatis videbuntur, quantum putas inesse iis gratiae, quae et a te et Graece proferuntur! Vale.

\section{Caio Plínio saúda Arrio Antonino}

1 De que modo posso melhor te mostrar o quanto admiro de fato teus epigramas gregos senão por ter tentado emular e traduzir alguns ao latim? muito inferiormente, por certo. O que deveu-se primeiro pela incompetência de meu engenho, depois pela penúria, ou melhor, como dizia Lucrécio, pela indigência da língua pátria. 2 E se estes, que são latinos e meus, te parecerem possuir algo de beleza, quanta graça não crês que haverá naqueles que são produzidos por ti e em grego! Fica bem! 


\section{Epistula V, 15}

C. Plinius Arrio Antonino suo s.

1 Cum versus tuos aemulor, tum maxime quam sint boni experior. Ut enim pictores pulchram absolutamque faciem raro nisi in peius effingunt, ita ego ab hoc archetypo labor et decido. 2 Quo magis hortor, ut quam plurima proferas, quae imitari omnes concupiscant, nemo aut paucissimi possint. Vale.

\section{Caio Plínio saúda Arrio Antonino}

1 Quando emulo teus versos, experimento ao máximo o quanto são bons. Assim como os pintores raramente reproduzem uma face bela e perfeita em si senão de um modo inferior, também eu me afasto do modelo e o arruino. 2 Por isso, te exorto ainda mais a produzires muitos mais, os quais todos desejam imitar, mas ninguém ou pouquíssimos o conseguem. Fica bem!

Tradução de:

Mauri Furlan

maurizius@gmail.com

Prof. Dr., Universidade Federal de Santa Catarina

Fonte: Pliny the Younger. Letters. With an English translation by William Melmoth. In two volumes. The Loeb Classical Library. London: William Heinemann, 1927.

http://perseus.mpiwg-berlin.mpg.de/cgibin/ptext?doc $=$ Perseus\%3Atext\%3A1999.02.0139\&layout $=\& l o c=7.9$ http://perseus.mpiwg-berlin.mpg.de/cgibin/ptext $?$ doc $=$ Perseus\%3Atext\%3A1999.02.0139\&layout $=\& l o c=4.18$ http://perseus.mpiwg-berlin.mpg.de/cgibin $/$ ptext $?$ doc $=$ Perseus\%3Atext\%3A1999.02.0139\&layout $=\& l o c=5.15$ 